OPEN ACCESS

Edited by:

Morenike Oluwatoyin Folayan, Obafemi Awolowo University, Nigeria

Reviewed by:

Andy Wai Kan Yeung The University of Hong Kong,

Hong Kong, SAR China Olubukola Olatosi, University of Lagos, Nigeria

*Correspondence:

Jiancheng Wang wangyh2415@126.com

tThese authors have contributed equally to this work and share first

authorship

Specialty section:

This article was submitted to

Children and Health,

a section of the journa

Frontiers in Pediatrics

Received: 25 November 2020

Accepted: 16 August 2021

Published: 09 September 2021

Citation:

Wang Y, Liu Q, Chen Y, Qian Y, Pan B, Ge L, Wang $Q$, Ding $G$ and Wang J (2021) Global Trends and Future

Prospects of Child Nutrition: A Bibliometric Analysis of Highly Cited Papers. Front. Pediatr. 9:633525 doi: 10.3389/fped.2021.633525

\section{Global Trends and Future Prospects of Child Nutrition: A Bibliometric Analysis of Highly Cited Papers}

\author{
Yunhua Wang ${ }^{1,2 \dagger}$, Qiaorong Liu ${ }^{2 \dagger}$, Yongcong Chen ${ }^{3}$, Yaling Qian ${ }^{3}$, Bei Pan ${ }^{2}$, Long $\mathrm{Ge}^{3,4}$, \\ Qi Wang ${ }^{3,4}$, Guowu Ding ${ }^{3}$ and Jiancheng Wang ${ }^{2 *}$ \\ ${ }^{1}$ School of Management, Lanzhou University, Lanzhou, China, ${ }^{2}$ Gansu Provincial Hospital, Lanzhou, China, ${ }^{3}$ Department of \\ Social Medicine and Health Management, School of Public Health, Lanzhou University, Lanzhou, China, ${ }^{4}$ Evidence Based \\ Social Science Research Center, School of Public Health, Lanzhou University, Lanzhou, China
}

Child nutrition has always been a global concern. This study performed visual analysis of 1,398 child nutrition highly cited papers (HCPs) from 2009 to 2019. The purpose of the study was to evaluate and present the performances of authors, journals, countries, institutions, top cited papers; to explore the hot topics, prospects, and to propose the future research directions on child nutrition. We used bibliometric methods to conduct indepth statistical analysis of HCPs on child nutrition, showing research progress, trends and hot spots. We included HCPs on child nutrition from the Science Citation IndexExpanded (SCI-E) database February 7, 2020. Two tools, CiteSpace and VOSviewer, were used to conduct the bibliometric analyses. The results showed that, since 2011, the number of HCPs on child nutrition has increased rapidly. The top three contributors in this field were the USA, the UK and Canada. However, the contribution of developing countries was very limited. Intestinal microflora, food allergy, overweight and obesity were the three major research hotspots in this field. Results of this study provide valuable references for ongoing child nutrition related research, which may be interesting and noteworthy to the researchers involved.

Keywords: child nutrition, bibliometric analysis, highly cited papers, intestinal microflora, obesity

\section{INTRODUCTION}

Child nutrition has always been a global concern. The United Nations International Children's Emergency Fund (UNICEF) released a report in 2019 about children, food and nutrition, entitled "The State of the World's Children in 2019" (1). The report mentioned that one-third of the world's children under the age of five still cannot get the nutrition they need to grow up currently. At the same time, the burden of malnutrition has become increasingly prominent (2-4). Among the global children under five, there are still 149 million stunted, and nearly 50 million children are in a state of wasting. Three hundred and forty million children face vitamin and mineral deficiencies, which is also known as "hidden hunger" (5). The problem of overweight is developing rapidly (6). Lack of necessary nutrients which may weaken the immune system, cause visual and hearing impairments and may also cause obesity. Studies have shown that the average lifetime income loss per child with growth retardation was $\$ 1,400$, and in developed countries, it was as high as $\$ 30,000$ (7). Overweight and obesity-related diseases, including heart disease, cancer, diabetes, and chronic respiratory diseases, was projected to cost more than $\$ 7$ trillion in low and middle-income countries between 2011 and 2025 (7-12). 
Carrying out scientific research on child nutrition can guide children to take in nutrition reasonably and promote children's healthy growth and development. Black's et al. paper "Global, regional, and national causes of child mortality in 2008: a systematic analysis" conducted a systematic analysis of global causes of child mortality in 2008, and found that nutrition was crucial to guide global efforts to improve child survival (13). Pries's et al. paper "Snack food and beverage consumption and young child nutrition in low-and middle-income countries: A systematic review" believed that although snacks could provide important nutrients for young children during the complementary feeding period, consumption of energy-dense, nutrient-poor snack foods and sugar-sweetened beverages (SSB) influences undernutrition and overnutrition among young children (14). Robertson's et al. paper "The Human Microbiome and Child Growth-First 1,000 Days and Beyond" found that an "undernourished" microbiome is intergenerational, thereby perpetuating growth impairments into successive generations, which may contribute to lifelong and intergenerational deficits in growth and development (15). The results of the above papers have greatly promoted the research on children's health, and have been cited by relevant scholars for many times. Highly cited papers (HCPs) in the Essential Science Indicators database refer to papers with citations in the top $1 \%$ of all papers in a research field, and they are considered to be symbols of scientific excellence and top performance of the past 10 years (16). The identification of HCPs on child nutrition could reflect the research progress and hot topics in this field accurately, which has an important reference to relevant scholars $(16,17)$. Bibliometric analysis is description of the external characteristics of the literature through mathematical and statistical methods, mainly based on the content of published journal papers as the main research object, and descriptive statistics on the academic status, such as journal distribution and main research institutions. Bibliometric analysis is one of the more effective research methods for evaluating the development stage of the discipline and predicting the future development trend $(18,19)$.

\section{METHODOLOGY}

\section{Data Source and Search Strategy}

We searched the Science Citation Index-Expanded (SCI-E) database on February 7, 2020. The specific retrieval strategy can be found in the Supplementary Material. The initial search yielded a total of 214,264 papers in the period from 1980 to the present. Among them, we chose the selection of "highly cited" in the field. Finally, 1,398 researches were included. There are no limitations on language, publication year, data category, and document type.

\section{Analysis Method}

In this research, CiteSpace and VOSviewer tools were used to analyze the publication characteristics, including paper type, language and quantity, active authors, countries and institutions, journals, co-cited journals and co-cited references, co-occurrence keywords and burst keywords, and form social network maps

Abbreviations: HCPs, highly cited papers.
(SNMs) based on the characteristics of the papers published (20-23). Due to the particularity of data format requirements of CiteSpace software, the selected literature was exported in the format of "RefWorks," the data was saved in the format of "Download_XXX", and imported into CiteSpace. Set the "Years Per Slice" length to "1," the "Terms Types" to "Burst Terms," and the "Pruning" to "Pathfinder." Meanwhile, the selected literature was downloaded in the format of "TXT" and imported into VOSviewer software. The data type was set to "Create a map based on bibiographic data" and the data source was set to "Read data from bibliographic database files." Different nodes represent different elements such as authors, countries, institutions, and keywords in a cluster map. The size of nodes indicates the number of publications or cooccurrence times of keywords. The lines between nodes reflects the relations of cooperation, co-occurrence, or co-citations. Nodes and lines of the same color represent the same cluster (24, 25). Microsoft Excel 2016 was used to conduct data aggregation and analysis.

\section{RESULTS}

\section{Paper Type, Language and Quantity}

A total of 1,398 HCPs were retrieved from SCI-E, which includes 944 (67.525\%) full-length research articles and $454(32.475 \%)$ reviews. Most of the papers 1,394 (99.714\%) were published in English, followed by $2(0.143 \%)$ were published in German and 2 $(0.143 \%)$ were published in Spanish.

The HCPs on child nutrition were published in 2009 (92 papers) and exceeded 100 papers in 2010 (Figure 1). In 2011, the number of publications decreased (103 papers). Since 2012, the number of publications increased by more than 30 (135 papers) and the growth rate continues slowly and steadily to 2017 (155 papers). The number of publications dropped significantly in 2018 and $<100$ papers in 2019 (Incomplete statistics). In this study, the relationship between the publication year and the number of publications is described using a polynomial model. There is a significant correlation between the number of studies and the year with a high coefficient of determination $\left(R^{2}\right.$ $=0.9109$ ).

\section{Active Authors, Countries, and Institutions}

The HCPs on child nutrition included 7,868 authors. The top 10 authors and co-cited authors were shown in Table 1. Tremblay has published the most, 17 (1.22\%) papers, following Victora with 14 (1.00\%) publications. The third were Lawlor and Bhutta both 12 publications $(0.86 \%)$, following Black 11 publications $(0.79 \%)$ and Smith 10 publications $(0.72 \%)$. The other 4 authors all published fewer than 10 publications. The highest co-cited author was World Health Organization (621 co-citations), the remaining co-cited authors were Ogden (183 co-citations), Victora (135 co-citations), Deonis (132 co-citations), Cole (127 co-citations), Sallis (119 co-citations), Flegal (112 co-citations), and Kramer (107 co-citations). Other co-cited authors both 100 co-citations.

In total, 113 countries published papers in this study. The top 10 countries and institutions were shown in Table 2, with the USA ranked first, accounting for $59.87 \%$ and the UK ranked second (362 publications, 25.89\%), followed by 


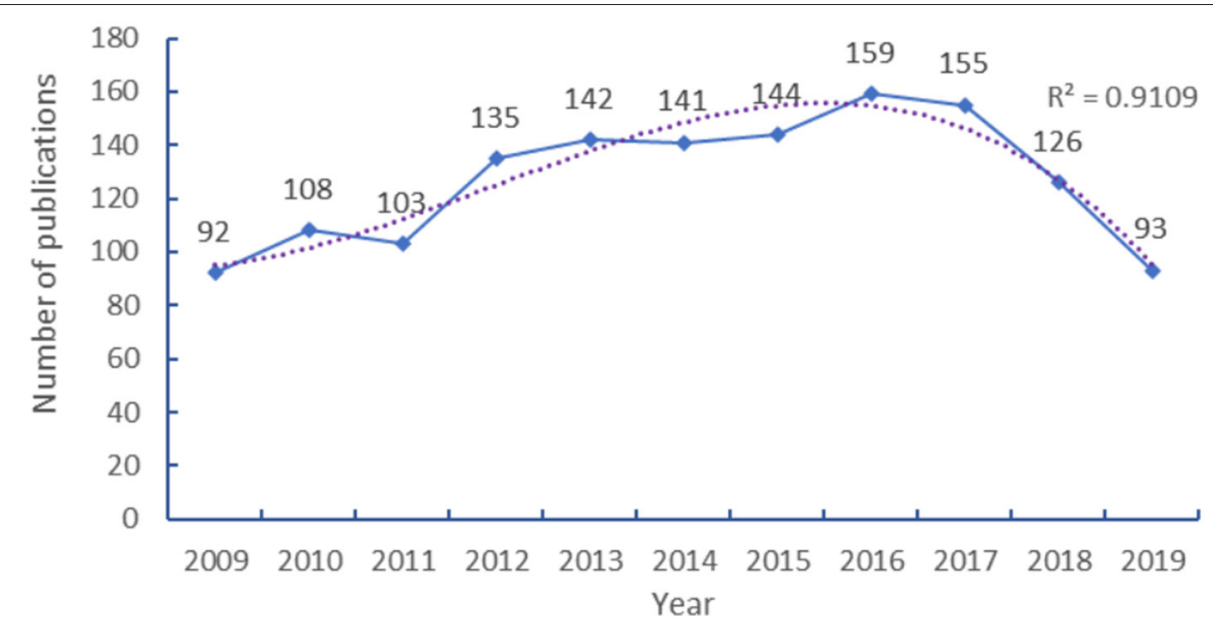

FIGURE 1 | Publication years for HCPs on child nutrition.

TABLE 1 | The top 10 authors and co-cited authors [ $n(\%)]$.

\begin{tabular}{llllll}
\hline Rank & Author & $\mathbf{N}(\%)$ & Country & Co-cited author & Country \\
\hline 1 & Tremblay, MS & $17(1.22)$ & Canada & World Health Organization & - \\
2 & Victora, CG & $14(1.00)$ & Brazil & Ogden, CL & USA \\
3 & Lawlor, DA & $12(0.86)$ & UK & Victora, CG & Brazil \\
4 & Bhutta, ZA & $12(0.86)$ & Canada & de Onis, M & Switzerland \\
5 & Black, RE & $11(0.79)$ & USA & Cole, TJ & UK \\
6 & Smith, GD & $10(0.72)$ & UK & Sallis, JF & 183 \\
7 & Chaput, JP & $9(0.64)$ & Canada & Flegal, KM & 132 \\
8 & Daniels, SR & $9(0.64)$ & USA & Kramer, MS & 127 \\
9 & Katzmarzyk, PT & $8(0.57)$ & USA & Black, RE & USA \\
10 & Ogden, CL & $8(0.57)$ & USA & Holick, MF & Canada \\
\hline
\end{tabular}

Canada (200 publications, 14.31\%), Australia (161 publications, $11.52 \%$ ), Switzerland (133 publications, 9.51\%), Netherlands (127 publications, 9.08\%), Germany (113 publications, 8.08\%), France (101 publications, 7.22\%). The other countries Italy and Spain both published $<100$ publications. As shown in Figure 2, the 59 countries with more than 4 papers were divided into 4 categories, with close cooperation among them.

Countries and institutions with greater influence and the status of cooperation could be displayed through the network maps. Two thousand four hundred eighty-two institutions contributed to the publications of this research. Table 3 showed the top 10 institutions. Harvard University ranked first (85 publications, 6.08\%), followed by University of North Carolina (56 publications, 4.01\%), University of Washington (48 publications, 3.43\%), Center for Disease Control and Prevention (43 publications, 3.07\%), University of Toronto (41 publications, 2.93\%). The University of California, San Francisco and the World Health Organization published the same amount of papers (40 publications, 2.86\%). Duke University and Emory University published the same amount of papers (39 publications, $2.79 \%$ ). The 10th University of Pennsylvania published $38(2.72 \%)$.

The cooperation of institutions with more than 10 papers was shown in Figure 3. Major research institutions were divided into 5 clusters, and close collaboration between the groups.

\section{Journals, Co-cited Journals and Co-cited References}

The study was published in 423 journals. The top 10 journals and co-cited journals, as well as the journal citation frequency, publishing countries and impact factor (IF) in 2019 could be seen in Table 3. The most published journal was Lancet (95 publications, 6.8\%), following New England Journal of Medicine (67 publications, 4.79\%), Pediatrics (43 publications, 3.08\%), Journal of American Medical Association (37 publications, 2.65\%), Cochrane Database of Systematic Reviews (29 publications, 2.07\%). Six of the top 10 journals were from the UK and others from the USA. "Citation/N" represents the average citations per paper. The Lancet ranked the highest because the average citation frequency of papers published in the journal was 648.33 times.

Lancet was the most co-citation (2,994 co-citations), followed by The American Journal of Clinical Nutrition (2,620 co-citations) and Pediatrics (2,581 co-citations). Among the top 10 co-cited journals, 7 are from the USA. Table 4 shows the top 10 co-cited references related to this research. The co-citation can reflect the researchers' attention. One paper was co-cited more than 60 times (26). Two papers were co-cited between 35 and 60 times $(27,28)$. Others were co-cited between 30 and 35 times (29-35). The top $20 \mathrm{HCPs}$ are shown in Figure 4. Papers with a high frequency of citations are represented by red bars, and with a 
TABLE 2 | The top 10 countries and institutions $[n(\%)]$.

\begin{tabular}{lllll}
\hline Rank & Country & $\boldsymbol{N}(\%)$ & Institution & N (\%) \\
\hline 1 & USA & $837(59.87)$ & Harvard University & $85(6.08)$ \\
2 & UK & $362(25.89)$ & University of North Carolina & $56(4.01)$ \\
3 & Canada & $200(14.31)$ & University of Washington & $48(3.43)$ \\
4 & Australia & $161(11.52)$ & Center for Disease Control and Prevention & $43(3.07)$ \\
5 & Switzerland & $133(9.51)$ & University of Toronto & $41(2.93)$ \\
6 & Netherlands & $127(9.08)$ & University of California, San Francisco & $40(2.86)$ \\
7 & Germany & $113(8.08)$ & World Health Organization & $40(2.86)$ \\
8 & France & $101(7.22)$ & Duke University & $39(2.79)$ \\
9 & Italy & $96(6.87)$ & Emory University & $39(2.79)$ \\
10 & Spain & $83(5.94)$ & University of Pennsylvania & $38(2.72)$
\end{tabular}

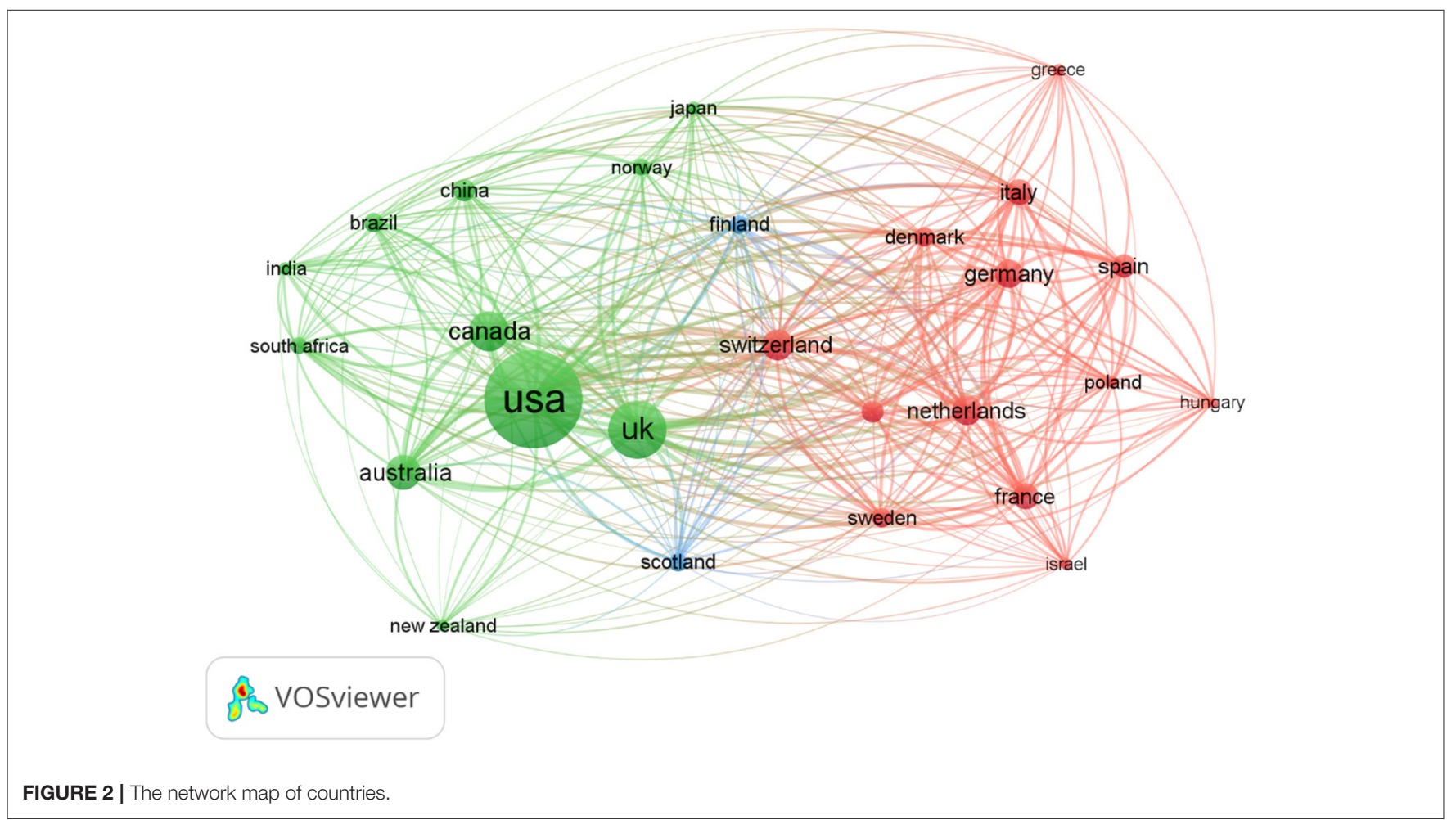

low frequency of citations are represented by green bars. The first reference with citation bursts appeared in 2009, $85.00 \%$ were first discovered between 2009 and 2011. After 2009, 3 HCPs were detected with citation burst.

\section{Co-occurrence Keywords and Burst Keywords}

We summarized and counted the keywords from the 1,398 HCPs. Figure 5 showed the visualization of color spectral density based on keywords and hotspot intensity, where warm red represents the hot areas and cold blue represents the cold areas. Children, obesity, health, prevalence, risk, risk-factors, metabolic syndrome, united-states, physicalactivity, and adolescents were the keywords with the highest density.
The cluster map of the main keywords was shown in Figure 6. Four clusters were formed by these keywords. Cluster 1 was the largest of the four clusters, including 19 keywords, mainly focused on intestinal flora and physical health in children. Cluster 2 included 15 keywords, primarily focused on children's food intake and the prevention of food allergies. Cluster 3 included 14 keywords, mainly focused on the adverse outcomes of children who are overweight or obese. Cluster 4 included 6 keywords, mainly focused on the prevalence of overweight children in the USA.

The map of burst keywords was shown in Figure 7 to identify hot topics. The time period that represents the strongest citation bursts was indicated in red bar. Among them, 8 keywords were detected in 2009. In this period, Vitamin D supplements, obesity-related complications such as diabetes, coronary heart 


\begin{tabular}{|c|c|c|c|c|c|c|c|c|c|c|}
\hline Rank & Journals & $N(\%)$ & Citations & $\begin{array}{c}\text { Citation } / N \\
\text { (average citation) }\end{array}$ & Country & IF (2019) & Co-cited journals & Co-citation & Country & IF (2019) \\
\hline 1 & Lancet & $95(6.80)$ & 61,591 & 648.33 & UK & 60.392 & Lancet & 2,994 & UK & 60.392 \\
\hline 2 & $\begin{array}{l}\text { New England Journal } \\
\text { of Medicine }\end{array}$ & $67(4.79)$ & 22,337 & 333.39 & UK & 74.699 & $\begin{array}{l}\text { American Journal of } \\
\text { Clinical Nutrition }\end{array}$ & 2,620 & USA & 6.766 \\
\hline 3 & Pediatrics & $43(3.08)$ & 11,975 & 278.49 & USA & 5.359 & Pediatrics & 2,581 & USA & 5.359 \\
\hline 4 & $\begin{array}{l}\text { Journal of American } \\
\text { Medical Association }\end{array}$ & $37(2.65)$ & 18,652 & 504.11 & USA & 45.540 & $\begin{array}{l}\text { New England Journal of } \\
\text { Medicine }\end{array}$ & 1,889 & UK & 74.699 \\
\hline 5 & $\begin{array}{l}\text { Cochrane Database of } \\
\text { Systematic Reviews }\end{array}$ & $29(2.07)$ & 6,415 & 221.21 & UK & 7.890 & $\begin{array}{l}\text { Journal of Allergy and } \\
\text { Clinical Immunology }\end{array}$ & 1,575 & USA & 10.228 \\
\hline 6 & $\begin{array}{l}\text { International Journal of } \\
\text { Behavioral Nutrition } \\
\text { and Physical Activity }\end{array}$ & $27(1.93)$ & 5,510 & 204.07 & UK & 6.714 & $\begin{array}{l}\text { Journal of the American } \\
\text { Medical Association }\end{array}$ & 1,504 & USA & 45.540 \\
\hline 7 & Obesity Reviews & $26(1.86)$ & 5,734 & 220.54 & UK & 7.310 & $\begin{array}{l}\text { International Journal of } \\
\text { Obesity }\end{array}$ & 1,247 & UK & 4.419 \\
\hline 8 & $\begin{array}{l}\text { Journal of Allergy and } \\
\text { Clinical Immunology }\end{array}$ & $21(1.50)$ & 7,290 & 347.14 & USA & 10.228 & PLoS One & 1,178 & USA & 2.740 \\
\hline 9 & $\begin{array}{l}\text { American Journal of } \\
\text { Preventive Medicine }\end{array}$ & $20(1.43)$ & 3,407 & 170.35 & USA & 4.420 & Journal of Nutrition & 1,089 & USA & 4.281 \\
\hline 10 & $\begin{array}{l}\text { International Journal of } \\
\text { Epidemiology }\end{array}$ & $20(1.43)$ & 4,281 & 214.05 & UK & 7.707 & $\begin{array}{l}\text { Journal of Pediatric } \\
\text { Surgery }\end{array}$ & 1,025 & USA & 1.919 \\
\hline
\end{tabular}




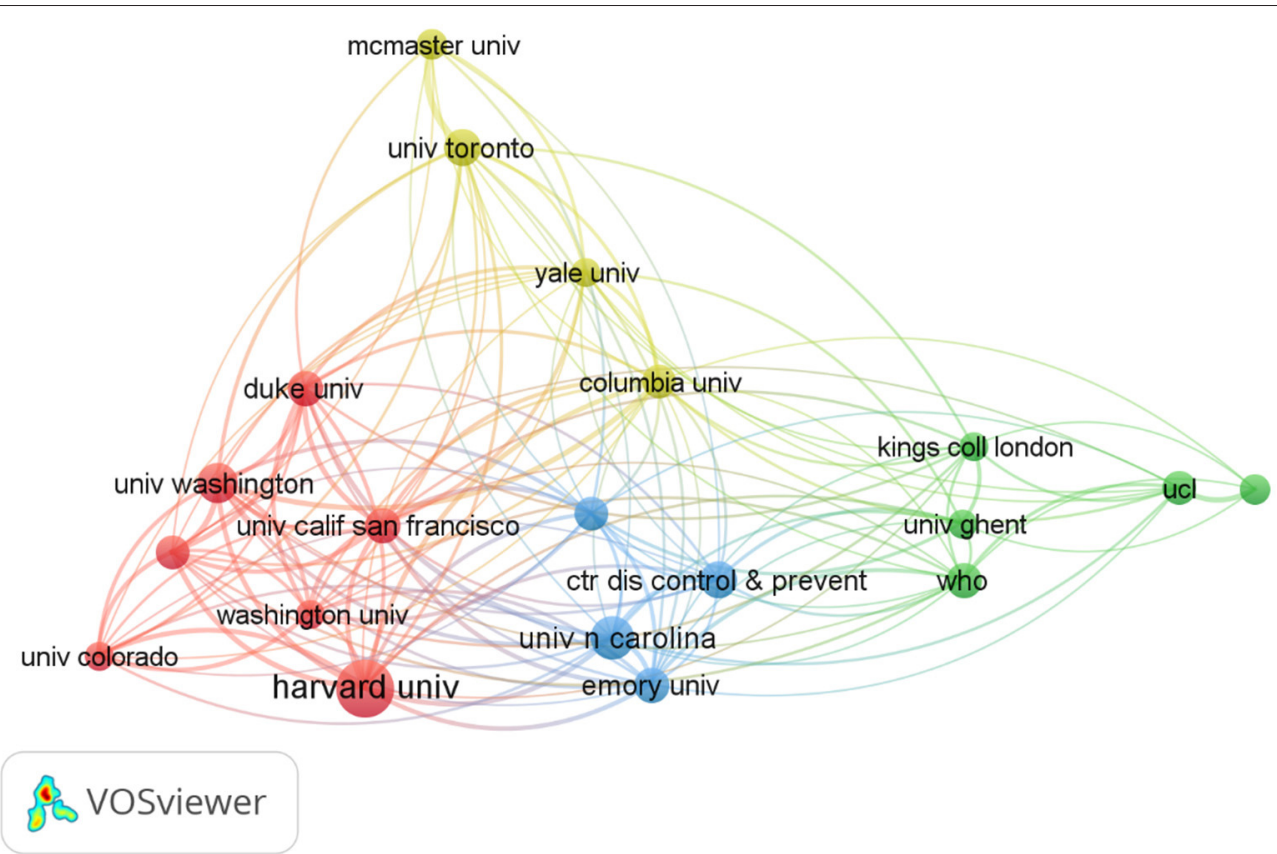

FIGURE 3 | The network map of institutions.

TABLE 4 | Top 10 co-cited references.

\begin{tabular}{|c|c|c|}
\hline Rank & Co-cited reference & Co-citation \\
\hline 1 & $\begin{array}{l}\text { Black, R. E. (2008). Maternal and child undernutrition: global and regional exposures and health consequences. Lancet. 371:243-60 } \\
\text { (26) }\end{array}$ & 63 \\
\hline 2 & $\begin{array}{l}\text { Black, R. E. (2013). Maternal and child undernutrition and overweight in low-income and middle-income countries. Lancet. } \\
\text { 382:427-51 (27) }\end{array}$ & 38 \\
\hline 3 & $\begin{array}{l}\text { Cole, T. J. (2000). Establishing a standard definition for child overweight and obesity worldwide: international survey. BMJ. } \\
\text { 320:1240-63 (28) }\end{array}$ & 37 \\
\hline 4 & Egger, M. (1997). Bias in meta-analysis detected by a simple, graphical test. BMJ. 315:629-34 (29) & 34 \\
\hline 5 & $\begin{array}{l}\text { Ng, M. (2014). Global, regional, and national prevalence of overweight in children and adults during 1980-2013: a systematic analysis } \\
\text { for the Global Burden of Disease Study 2013. Lancet. 384:766-81 (30) }\end{array}$ & 34 \\
\hline 6 & Ogden, C. L. (2006). Prevalence of overweight and obesity in the United States, 1999-2004. JAMA. 295:1549-55 (31) & 33 \\
\hline 7 & Ogden, C. L. (2015). Prevalence of Childhood and Adults in the United States, 2011-2012. JAMA. 311:806-14 (32) & 32 \\
\hline 8 & Turnbaugh, P. J. (2006). An obesity-associated gut microbiome with increased capacity for energy harvest. Nature. 444:1027-31 (33) & 31 \\
\hline 9 & Victora, C. G. (2008). Maternal and child undernutrition: consequence for adult health and human capital. Lancet. 371:340-57 (34) & 31 \\
\hline 10 & Yatsunenko, T. (2012). Human gut microbiome viewed across age and geography. Nature. 486:222-57 (35) & 30 \\
\hline
\end{tabular}

disease, and the National Health and Nutrition Examination Survey (NHANES) findings were hot research topics. From 2010 to 2014, metabolic syndrome, steatohepatitis, insulin resistance, low birth weight and the establishment of models and environments to promote children's health, were major concerns. After 2014, no prominent keywords were detected.

\section{DISCUSSION}

\section{Analysis of Paper Types and Publication Year}

There were two types of HCPs included in this study, with reviews accounted for $32.475 \%$. This phenomenon means that a lot of summaries and conclusions has been completed by researchers on the basis of existing research. This was undoubtedly great progress. Thus, we were confident that the number of studies on child nutrition will continue to increase, with greater content in the future. This trend will create more awareness and draw attention to children's nutrition and health globally.

The included HCPs were published from 2009 to 2019. Before 2012, the number of published HCPs was in a state of slow growth, and $<130$, which suggested that the development of child nutrition research was slow during the period, and researchers did not realize the importance of children's nutrition and health. After 2012, HCPs began to growth slowly and reached peak of 159 in 2016. This may be due to the fact that the WHO Child Growth Standards demonstrate that, by the time children reach the age of five, differences are more affected by nutrition, 


\section{References}

Timperio A, 2004, PREV MED, V38, P39, DOI

Baker JL, 2007, NEW ENGL J MED, V357, P2329, DOI

James J, 2004, BMJ-BRIT MED J, V328, P1237, DOI

Schwimmer JB, 2006, PEDIATRICS, V118, P1388, DOI

Epstein LH, 2008, ARCH PEDIAT ADOL MED, V162, P239, DOI

Sicherer SH, 2003, J ALLERGY CLIN IMMUN, V112, P1203, DOI

Weiss R, 2004, NEW ENGL J MED, V350, P2362, DOI

Natl High Blood Pressure Educ Prog, 2004, PEDIATRICS, V114, P55

Whitaker RC, 2004, PEDIATRICS, V114, P0, DOI

Ferrari J, 2009, COCHRANE DB SYST REV, V0, P0, DOI

Ogden CL, 2006, JAMA-J AM MED ASSOC, V295, P1549, DOI

Ogden CL, 2008, JAMA-J AM MED ASSOC, V299, P2401, DOI

Ogden CL, 2002, JAMA-J AM MED ASSOC, V288, P1728, DOI

Furuta GT, 2007, GASTROENTEROLOGY, V133, P1342, DOI

Strong WB, 2005, J PEDIATR-US, V146, P732, DOI

Holick MF, 2007, NEW ENGL J MED, V357, P266, DOI

Olshansky SJ, 2005, NEW ENGL J MED, V352, P1138, DOI

Marshall SJ, 2004, INT J OBESITY, V28, P1238, DOI

Summerbell CD, 2005, COCHRANE DB SYST REV, V0, P0, DOI

Wang Y, 2006, INT J PEDIATR OBES, V1, P11, DOI

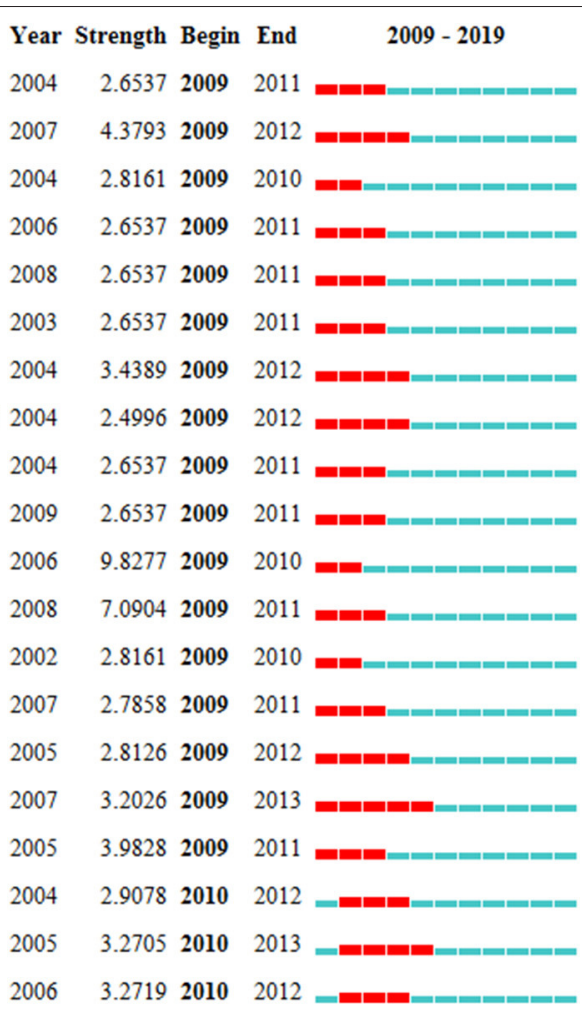

FIGURE 4 | Top 20 references with the strongest citation burst.

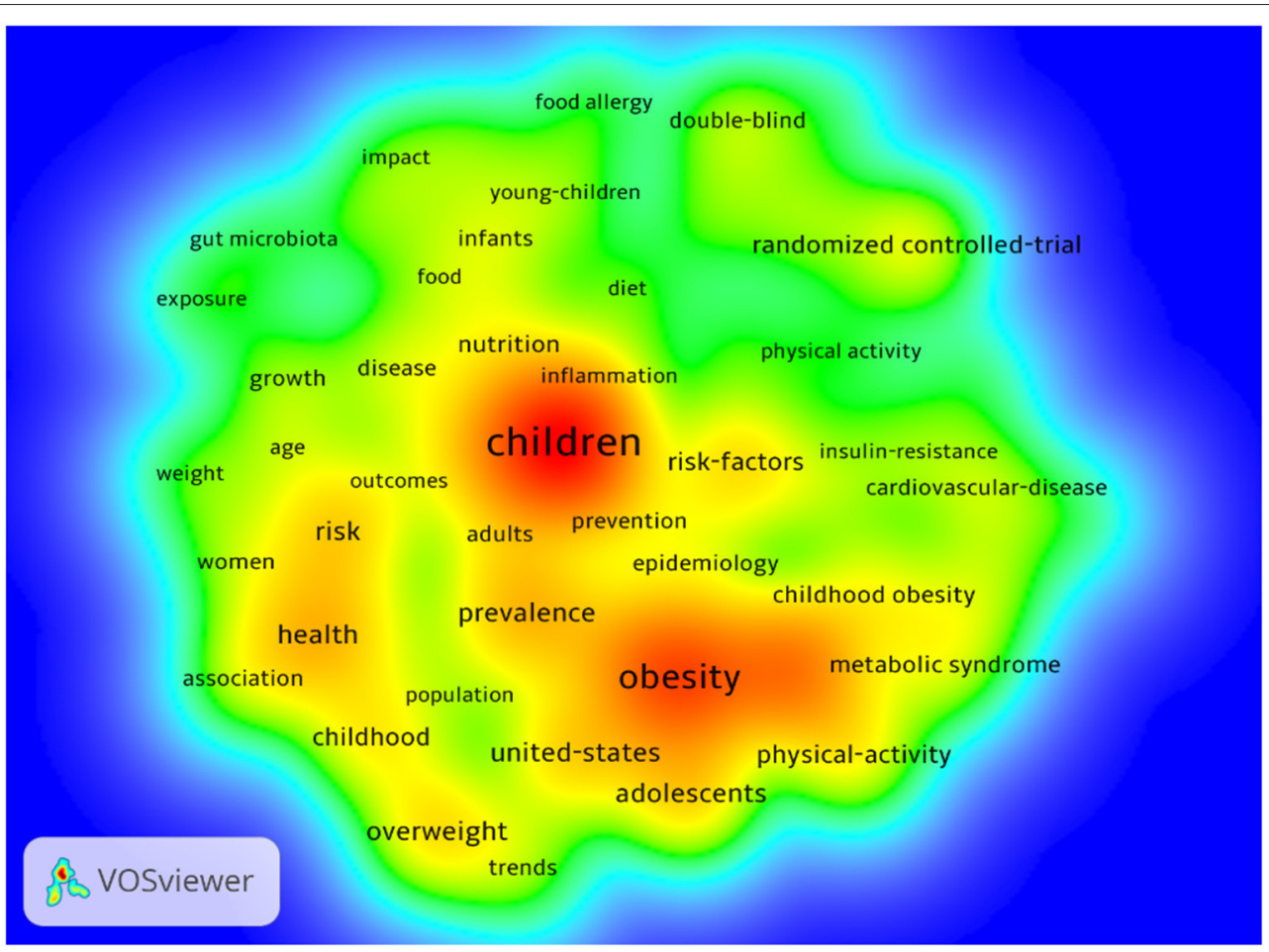

FIGURE $\mathbf{5}$ | The density map of keywords. 


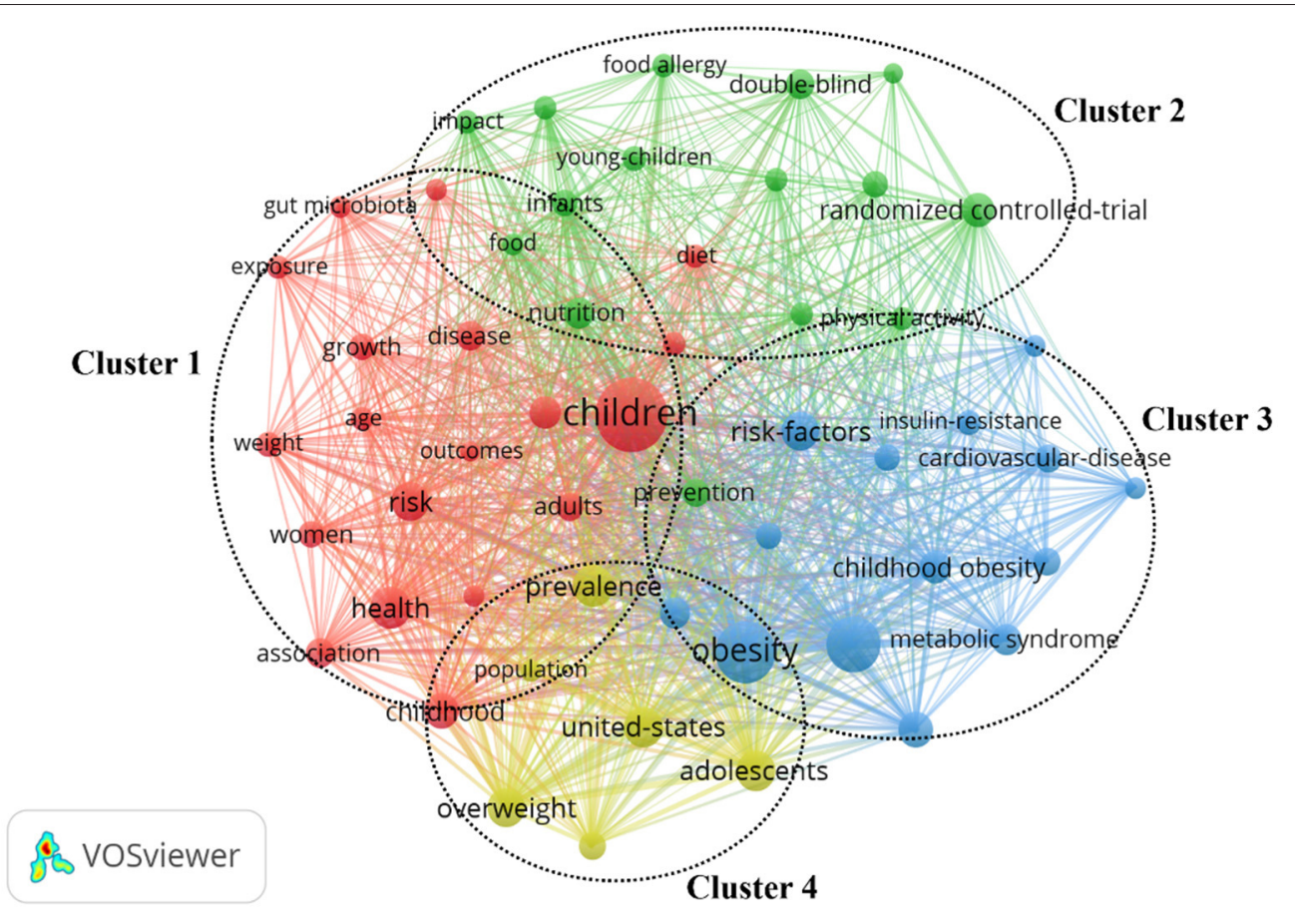

FIGURE 6 | The network map of keywords.

feeding methods, environment, and health care than by genetic or racial characteristics, and the Ninth Global Conference on health promotion focused on global childhood obesity $(36,37)$. After 2016, the number of HCPs has shown a decreasing trend. In general, the number of publications ranged from 90 to 160 annually.

\section{The Geographical Distribution of Research Group}

Among 1,398 HCPs included, 7,868 authors involved. But only 6 $(0.08 \%)$ authors have published more than 10 papers. Sixty-one $(0.78 \%)$ authors have published more than 5 papers. Statistical results showed that $6,865(87.25 \%)$ authors published only 1 paper. This reflects that few researchers have been committed to child nutrition and health.

Among the top 10 authors, 3 from Canada, Tremblay, Bhutta, and Chaput. They have published 38 HCPs in total. The reason might be that Tremblay, as a leader, has published many papers on the prevalence and long-term changes in overweight and obesity about Canadian children and adolescents. Tremblay and Chaput have been working closely together and have published several papers on children's physical activity to control overweight and obesity. Among them, Systematic review of sedentary behavior and health indicators in school-aged children and youth, published by Tremblay et al. was cited the most (38), more than 800 times. Among the top 10 co-cited authors, 5 from the USA, and the total number of citations was 614. Prevalence of Childhood and Adult Obesity in the United States, 2011-2012, published by Ogden et al. (32); Prevalence and Trends in Obesity
Among US Adults, 1999-2008, published by Flegal et al. (39); Maternal and child undernutrition and overweight in low-income and middle-income countries, published by Black et al. (27); Evaluation, Treatment, and Prevention of Vitamin D Deficiency: an Endocrine Society Clinical Practice Guideline, published by Holick et al. (40) has been cited more than 1,000 times. This shows that the active and influential scholars are from Canada and the USA. Interestingly, neither the top 10 authors nor the cocited authors have any scholars from China. Probably because: (1) Chinese scholars pay little attention to child nutrition; (2) The number and quality of papers published by Chinese scholars on child nutrition were small; (3) Chinese scholars had low English proficiency and obvious language barriers. Therefore, in the future, it is important for Chinese scholars to strengthen exchanges and cooperation with outstanding foreign scholars to learn advanced research methods, broaden their horizons and ideas.

Although child nutrition deserves global attention, 24.11\% of countries have only 1 highly cited paper. Among the top 10 countries with HCP on child nutrition, all included developed countries and no developing countries, which indicates that developing countries are lagging in this field. Among the top 10 institutions, 8 from the USA and 1 from Canada. This phenomenon showed that the USA was in a dominant position and there was a large gap between developing and developed countries in child nutrition research. In short, the global impact of developing countries on child nutrition is limited. There was need for collaborative efforts between high income countries and Low and Middle income countries (LMIC) to improve and carry 


\begin{tabular}{|c|c|c|c|c|c|}
\hline & Keywords & Year & Strength & Begin & $2009-2019$ \\
\hline & vitamin $\mathrm{d}$ & 2009 & 2.9388 & 2009 & 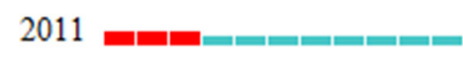 \\
\hline & randomized trial & 2009 & 2.7178 & 2009 & 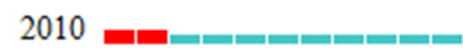 \\
\hline & walking & 2009 & 2.5929 & 2009 & 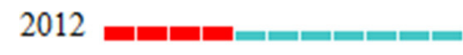 \\
\hline & diabetes mellitus & 2009 & 3.1191 & 2009 & 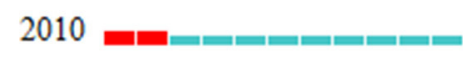 \\
\hline & african american & 2009 & 3.1566 & 2009 & 2011 \\
\hline & controlled trial & 2009 & 2.7178 & 2009 & 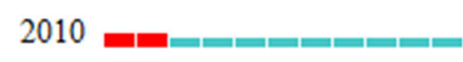 \\
\hline & nutrition examination survey & 2009 & 3.1566 & 2009 & 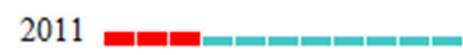 \\
\hline & coronary heart disease & 2009 & 2.4913 & 2009 & 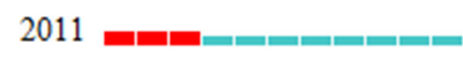 \\
\hline & consequence & 2009 & 2.6863 & 2010 & 2012 - \\
\hline & low birth weight & 2009 & 4.3512 & 2010 & 2013 - \\
\hline & us children & 2009 & 2.9597 & 2010 & 2013 - \\
\hline & metabolicsyndrome & 2009 & 2.5472 & 2010 & 2013 - \\
\hline & steatohepatiti & 2009 & 2.6936 & 2010 & 2011 - \\
\hline & energy intake & 2009 & 2.5515 & 2010 & 2014 - \\
\hline & 3 rd national health & 2009 & 2.6936 & 2010 & 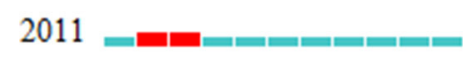 \\
\hline & insulin resistance & 2009 & 3.0341 & 2010 & 2012 - \\
\hline & pattern & 2009 & 3.6921 & 2011 & 2014 =ாடா \\
\hline & national health & 2009 & 3.3764 & 2011 & 2013 -மா \\
\hline & built environment & 2009 & 3.532 & 2011 & 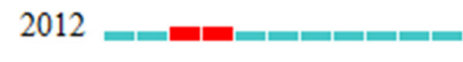 \\
\hline & disorder & 2009 & 2.5218 & 2011 & 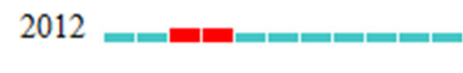 \\
\hline
\end{tabular}

out more high impact research in the areas of child nutrition especially among children in LMIC.

In terms of cooperation between countries, both the USA and the UK maintain close cooperation with 55 countries, Canada and Switzerland with 54 countries, respectively, followed by Australia and Belgium with 53 and 50 countries, respectively, while Slovakia did not cooperate with any country. It was noteworthy that, China has partnerships with 48 countries, so we are confident that China will be at the forefront on child nutrition in the future.

\section{Analysis of Published Sources}

The included 1,398 HCPs were published in 423 journals, each journal should publish an average of 3.30 papers, but in fact, $6.38 \%$ of journals published more than 10 papers and $58.16 \%$ of journals only published 1 paper. Four major journals published 242 papers, accounting for $17.32 \%$. These journals were as follows: Lancet (6.80\%), New England Journal of Medicine (4.79\%), Pediatrics (3.08\%), Journal of American Medical Association (2.65\%). The Lancet was the journal with the most productive and cited researches of HCPs on child nutrition. Among the authors, Black et al. (27) and Ng et al. (30) from the USA published many papers, and have been cited 2,568 times and 5,253 times, respectively. The unprecedented World Summit for Children, held at the United Nations headquarters in New York City in 1990, set out 10-year goals for children's health, nutrition and education (41); the special session on children held in 2002 reviewed the progress made in children's affairs since the 1990 World Summit for Children and reinvigorated the global commitment to children's rights (42). Through holding these international conferences, scholars have developed great interest on child nutrition, which has also aroused scholars' attention.

Among the top 10 journals, six were from the UK and none from China, which once again confirms the huge gap in scientific research between developing and developed countries. Citation $/ \mathrm{N}$ is an important index to measure the scientific 
importance or quality of a paper. It also shows that the quality of the journal is high and the content is attractive. The American Journal of Allergy and Clinical Immunology performed well. This journal were recognized and welcomed by scholars, because although the journal published only $21 \mathrm{HCPs}$, the citation /N was high, which also shows the high academic influence of the journal.

\section{Analysis of the Main Keywords Intestinal Flora and Physical Health}

In this study, one of the important research hotspots and directions was the composition and roles of intestinal microbiota in children (Figure 6, cluster 1). There are a large number of bacteria in the human gut, which together make up the intestinal flora. In the human body, cells and bacterial cells are symbiotic, and there are 10 times as many bacterial cells as there are human cells $(43,44)$. The effects of intestinal flora on the human body are mainly manifested as nutrient absorption, substance metabolism, and immune defense (45). Some minerals, such as calcium, iron, and magnesium, are absorbed by the body through the intestinal flora (46). The intestinal flora is also involved in the metabolism of certain substances by fermenting food, synthesizing exercise fatty acids and vitamin $\mathrm{K}$, which are then absorbed by the body (47). For children, intestinal bacteria can not only regulate the activity of cytotoxic $\mathrm{T}$ cells and natural killer cells, reduce the replication of viruses in cells, but also play an important role in innate immunity, activation of the immune system and the formation of an adaptive immune response $(48,49)$. Probiotics can significantly increase the expression of CD3 + CD4 + in children with severe HFMD caused by EV71, enhance the immune function of $\mathrm{T}$ cells and improve the cellular immune response of children. Therefore, intestinal flora plays an important role in children's growth. Gao et al. considered that the diversity of intestinal microflora in obese children was lower than that in normal children, and the relative abundance of intestinal flora at different classification levels was significantly different (50). Some studies have shown that the mode of delivery affects the bacterial community in the newborn gut. Guarino et al. noted in cesarean delivery, direct contact of the mouth of the newborn with vaginal and intestinal microbiota is replaced by exogenous non-maternally derived bacteria colonizing the infants' intestine producing a less diverse flora (51). Biasucci et al. believed that intestinal bacterial colonization of infants born by cesarean section is more likely to change (52). However, Rutayisire et al. considered that the diversity and colonization pattern of intestinal flora were significantly correlated with the mode of delivery 3 months before birth, but the difference disappeared after 6 months (53). Therefore, the diversity and colonization level of intestinal microflora and the mode of delivery as well as its extensive impact on the health of infants at all stages of life should be further studied.

\section{Prevention of Food Allergies}

Food allergies are common and affect about $8 \%$ of children in the United States. It brings a huge physiological, economic and social burden to children and families. There is no cure for food allergies (54). Therefore, the prevention and treatment of food allergy in children is also a key topic in recent years (Figure 6, cluster 2). Food allergies can be a variety of symptoms in children, with skin and gastrointestinal symptoms being the most common (55). Children under the age of 6 are often allergic to high-protein foods such as eggs, milk, peanut, and soy, as children's immune systems are not yet mature and the protective function of the gastrointestinal mucosa in infants is not perfect (56). Food allergies have a significant impact on the morbidity, living quality of infants and young children, which has become a concern for many parents (57). Peanut is one of the most common food allergies in children, which is becoming more and more common over time. So far, there is no effective treatment for peanut allergy, only through the use of epinephrine to avoid and alleviate this symptom. The double allergen exposure hypothesis suggested that the dermal sensitization of peanut may be the pathophysiological mechanism of peanut allergy development. In the future, oral and epicutaneous immunotherapy may be used as exciting tools to achieve peanut desensitization in children. In the past, people focused on the treatment of food allergy, but seldom considered the mental health consequences of living with the condition $(58,59)$. Feng et al. found that patients with food allergy may have depression, anxiety, post-traumatic stress, being bullied, and poor overall quality of life. At the same time, the patient's family life will also be disturbed (60). Parents of children with food allergies, especially mothers, report anxiety, depression, and decreased quality of life (61). Fong et al. stressed that children and adolescents with food allergies in the Australian population are vulnerable to bullying. It's a significant social problem that requires addressing to positively assist these children (62).

At present, in the treatment and prevention of food allergies, bacterial therapy has attracted more and more attention from scholars. They believe that one of the effective ways to prevent allergic diseases is fecal flora transplantation $(63,64)$.

\section{Overweight or Obesity in Children}

At present, childhood obesity is also widely concerned (Figure 6, cluster 3 and cluster 4). In 2017, the WHO announced that the number of obese children and adolescents aged 5 to 19 worldwide has increased ten-fold in the past 40 years. If the current trend continues, the number of obese children and adolescents will exceed the number of moderately or severely underweight by 2022 (64). American children's obesity rate ranks first in the world. Children with obesity may develop many serious comorbidities. These diseases include musculoskeletal diseases, cardiovascular diseases such as hypertension, insulin resistance and hyperlipidemia, respiratory diseases such as sleep apnea or asthma, and digestive system diseases such as nonalcoholic fatty liver disease $(65,66)$. Childhood obesity has a greater risk of persistence in adulthood. Low socioeconomic status, immigration background, and clinical susceptibility to obesity are the serious risk factors for obesity. However, the individual causes of obesity are quite complex, so it is necessary to make a systematic analysis of individual differences, and to formulate differentiated and realistic treatment plans. In addition to the rare monogenic or syndromic obesity, the treatment of childhood obesity should rely on professional 
lifestyle intervention programs. In general, a key component of a treatment strategy should include improving nutrition, physical exercise and self-esteem, while reducing stress. Besides, the inclusion of parents in treatment strategies has proved beneficial and necessary. Studies have shown that male children are 1.6 times more likely to be overweight/obesity than female children; children of overweight mothers are 3.34 times more likely to be overweight/obesity than children of normal weight mothers; preschool children's overweight/obesity is related to physical activity, screen time, eating snacks when watching TV, using computers, tablets and mobile phones (64).

Considering the individual differences between obese children and the complexity of obesity, there is no effective treatment for all groups. The most appropriate intervention method is determined by the age of children and the degree of overweight. The current methods of weight loss include lifestyle change interventions, bariatric surgery and drug use. Lifestyle change is the most widely used way to treat childhood obesity (67). This approach is designed to improve the quality of diet, increase physical activity and reduce sedentary behavior, usually using behavior change techniques to help maintain positive change and prevent recurrence. Many interventions focus on families, and parents are defined as "agents of change," especially among children under 12 (68). Bariatric surgery generally includes gastric shunt, sleeve gastrectomy and gastric banding (69). Currently, the drugs used to treat obesity include: (1) Sibutramine, an appetite inhibitor, which is still allowed in Brazil, was suspended by the European drug agency in 2010 due to its adverse cardiovascular effects, and was withdrawn by the US Food and Drug Administration (FDA) in 2010; (2) Orlistat, a fat absorption inhibitor, has been approved by the FDA, but only for children under the age of 12 . Other drugs often used to treat childhood obesity include the antidiabetic drug metformin and the antidepressant fluoxetine (67). New drugs for appetite regulation are currently under development or evaluation.

\section{CONCLUSIONS}

At present, more and more researches on child nutrition have been published. The bibliometric method could be used to systematically analyze the characteristics of the papers and show the research status, hot spots, and future development trends. The results showed that 6,865 authors $(87.65 \%)$ only published 1 paper. Scholars from the UK, the USA, and Canada had a greater academic influence. Scientific research institutions from the USA contributed the most. Strengthening academic exchanges and cooperation is the top priority for future development. Although great progress has been made, further research is needed to understand most of the unknown problems. Combining the above research results, the future development direction of children's nutrition research is put forward:

It has been concluded that the mode of delivery will affect the bacterial community in the intestinal tract of newborns. However, it is still controversial whether the adverse effects will last into childhood or even adulthood. Further research should be carried out in the future, because the results may affect pregnant women's choice of delivery mode.

Food allergies have a significant impact on the morbidity, living quality of children, but there is no effective treatment. The future research should focus on the induction of food allergy in children, the causes of sensitization, clinical manifestations, prognosis, precautions and so on, to solve this scientific problem.

Strengthen the research on the causes, types, prevention and targeted intervention measures of overweight or obesity in children. A large number of studies predict that the number of overweight or obese children will continue to increase in the future. Therefore, we should better understand the source of obesity and control the number and type of obesity children from the source.

\section{STRENGTHS AND LIMITATIONS}

According to our knowledge, this study is the first bibliometric analysis of highly cited articles on child nutrition. Therefore, the study is original. This study not only provide a historical perspective for future research, but also highlight research areas requiring further investigation and development. In addition, before literature search, we read a large number of high-level papers and extracted search terms related to child nutrition. After integration, we formulated the search strategy for this study. Therefore, the search strategy is complete and scientific. Of course, this study also has some shortcomings, the WOS database is considered the most critical data source in bibliometric analysis, so we only searched it (70), some studies may have been overlooked. Besides, there are many authors in this study, some authors may have the possibility of renaming or having the same author from different institutions. Although we have carefully proofread the process, some mistakes are inevitable.

\section{AUTHOR CONTRIBUTIONS}

JW designed this study. YW, QL, and YC performed search and collected data and wrote the manuscript. YQ rechecked data. BP and QW performed analysis. LG rechecked. JW and GD reviewed the manuscript. All authors contributed to the article and approved the submitted version.

\section{FUNDING}

This work was supported by the National Research Project Development Plan of Gansu Provincial Hospital (19SYPYB-18); Lanzhou Chengguan District Science and Technology Plan Project (2019RCCX0011).

\section{SUPPLEMENTARY MATERIAL}

The Supplementary Material for this article can be found online at: https://www.frontiersin.org/articles/10.3389/fped. 2021.633525/full\#supplementary-material 


\section{REFERENCES}

1. Martin CR, Custodio E, Yusuf A, Daniel M, Dominique F, Francois K. Malnutrition and morbidity trends in Somalia between 2007 and 2016: results from 291 cross-sectional surveys. BMJ Open. (2020) 10:e033148. doi: 10.1136/bmjopen-2019-033148

2. Bourassa MW, Osendarp SJM, Adu-Afarwuah S, Ahmed S, Ajello C, Bergeron $\mathrm{G}$, et al. Review of the evidence regarding the use of antenatal multiple micronutrient supplementation in low- and middle-income countries. Ann N Y Acad Sci. (2019) 1444:6-21. doi: 10.1111/nyas.14121

3. Zaidi S, Bhutta Z, Hussain SS, Rasanathan K. Multisector governance for nutrition and early childhood development: overlapping agendas and differing progress in Pakistan. BMJ Glob Health. (2018) 10:e000678. doi: 10.1136/bmjgh-2017-000678

4. Cesare MD, Sorić M, Bovet P, Miranda JJ, Bhutta Z, Stevens GA, et al. The epidemiological burden of obesity in childhood: a worldwide epidemic requiring urgent action. BMC Med. (2010) 17:212. doi: 10.1186/s12916-019-1449-8

5. Lucas JE, Richter LM, Daelmans B. Care for child development: an intervention in support of responsive caregiving and early child development. Child Care Health Dev. (2018) 44:41-9. doi: 10.1111/cch.12544

6. Ricci G, Tomassoni D, Pirillo I, Sirignano A, Sciotti M, Zaami S, et al. Obesity in the European region: social aspects, epidemiology and preventive strategies. Eur Rev Med Pharmacol Sci. (2018) 22:693039. doi: $10.26355 /$ eurrev_201810_16163

7. Bégin F, Aguayo VM. First foods: why improving young children's diets matter. Matern Child Nutr. (2017) 13 (Suppl. 2):e12528. doi: $10.1111 / \mathrm{mcn} .12528$

8. Prentice AM. Stunting in developing countries. World Rev Nutr Diet. (2018) 117:165-75. doi: 10.1159/000484505

9. Shetty P. Nutrition sensitive agriculture to achieve better nutritional outcomes. Eur J Clin Nutr. (2018) 72:1296-9. doi: 10.1038/s41430-018-0208-9

10. Kemps E, Goossens L, Petersen J, Verbeken S, Vervoort L, Braet C. Evidence for enhancing childhood obesity treatment from a dual-process perspective: a systematic literature review. Clin Psychol Rev. (2020) 77:101840. doi: 10.1016/j.cpr.2020.101840

11. Kralick AE, Zemel BS. Evolutionary perspectives on the developing skeleton and implications for lifelong health. Front Endocrinol. (2020) 11:99. doi: $10.3389 /$ fendo.2020.00099

12. Chen XP, Sridevi D. gut microbiome in obesity, metabolic syndrome, and diabetes. Curr Diab Rep. (2018) 18:129. doi: 10.1007/s11892-018-1104-3

13. Black RE, Cousens S, Johnson HL, Lawn JE, Rudan I, Bassani DG, et al. Global, regional, and national causes of child mortality in 2008: a systematic analysis. Lancet. (2010) 375:1969-87. doi: 10.1016/S0140-6736(10)60549-1

14. Pries AM, Filteau S, Ferguson EL. Snack food and beverage consumption and young child nutrition in low- and middle-income countries: a systematic review. Matern Child Nutr. (2019) 15:e12729. doi: 10.1111/mcn.12729

15. Robertson RC, Manges AR, Finlay BB, Prendergast AJ. The human microbiome and child growth - first 1000 days and beyond. Trend Microbiol. (2019) 27:131-47. doi: 10.1016/j.tim.2018.09.008

16. Ma Q, Li Y, Zhang Y. Informetric analysis of highly cited papers in environmental sciences based on essential science indicators. Int J Environ Res Public Health. (2020) 17:3781. doi: 10.3390/ijerph17113781

17. Ring J, Castanov V, McLaren C, Hajjar AEJ, Jeschke MG. Scientific impact and clinical influence: identifying landmark studies in burns. J Burn Care Res. (2020) 41:1240-52. doi: 10.1093/jbcr/iraa083

18. Chen H, Jiang W, Yang Y, Yan Y, Xin M. Global trends of municipal solid waste research from 1997 to 2014 using bibliometric analysis. J Air Waste Manage Assoc. (2015) 65:1161-70. doi: 10.1080/10962247.2015.1083913

19. Chen D, Liu Z, Luo Z, Webber M, Chen J. Bibliometric and visualized analysis of emergy research. Ecol Eng. (2016) 90:285-93. doi: 10.1016/j.ecoleng.2016.01.026

20. Chen C M, Dubin R, Kim M C. Orphan drugs and rare diseases: a scientometric review (2000-2014). Expert Opin Orphan Drugs. (2014) 2:70924. doi: $10.1517 / 21678707.2014 .920251$

21. Chen C. Searching for intellectual turning points: progressive knowledge domain visualization. Proc Natl Acad Sci USA. (2004) 101:5303-10. doi: 10.1073/pnas.0307513100
22. Zhang M, Gao M, Yue S, Zheng TL, Gao Z, Ma XY, et al. Global trends and future prospects of food waste research: a bibliometric analysis. Environ Sci Pollut Res. (2018) 25:24600-10. doi: 10.1007/s11356-018-2598-6

23. Ye J, Ding H, Ren J, Xia ZY. The publication trend of neuropathic pain in the world and China: a 20-years bibliometric analysis. J Headache Pain. (2018) 19:110. doi: 10.1186/s10194-018-0941-4

24. Liang YD, Li Y, Zhao J, Wang XY, Zhu HZ, Chen XH, et al. Study of acupuncture for low back pain in recent 20 years: a bibliometric analysis via CiteSpace. J Pain Res. (2018) 10:951-64. doi: 10.2147/JPR.S132808

25. Xie P. Study of international anticancer research trends via coword and document co-citation visualization analysis. Scientometrics. (2015) 105:61122. doi: 10.1007/s11192-015-1689-0

26. Black RE, Allen LH, Bhutta ZA, Caulfield LE, Onis MD, Ezzati $M$, et al. Maternal and child undernutrition: global and regional exposures and health consequences. Lancet. (2008) 371:243-60. doi: 10.1016/S0140-6736(07)61690-0

27. Black RE, Victora CG, Walker SP, Bhutta ZA, Christian P, Onis $\mathrm{MD}$, et al. Maternal and child undernutrition and overweight in low-income and middle-income countries. Lancet. (2013) 382:427-51. doi: 10.1016/S0140-6736(13)60937-X

28. Cole TJ, Bellizzi MC, Flegal KM, Dietz WH. Establishing a standard definition for child overweight and obesity worldwide: international survey. BMJ. (2000) 320:1240-63. doi: 10.1136/bmj.320.7244.1240

29. Egger M, Davey SG, Schneider M, Minder C. Bias in metaanalysis detected by a simple, graphical test. BMJ. (1997) 315:629-34. doi: 10.1136/bmj.315.7109.629

30. Ng M, Fleming T, Robinson M, Blake T, Graetz N, Margono C, et al. Global, regional, and national prevalence of overweight and obesity in children and adults during 1980-2013: a systematic analysis for the global burden of disease study 2013. Lancet. (2014) 384:766-81. doi: 10.1016/S0140-6736(14)60460-8

31. Ogden CL, Carroll MD, Curtin LR, Tabak CJ, Flegal KM. Prevalence of overweight and obesity in the United States, 1999-2004. JAMA. (2006) 295:1549-55. doi: 10.1001/jama.295.13.1549

32. Ogden CL, Carroll MD, Fryar CD, Flegal KM. Prevalence of obesity among adults and youth: United States, 2011-2014. NCHS Data Brief. (2015) 219:1-8.

33. Turnbaugh PJ, Ley RE, Mahowald MA, Magrini V, Mardis ER, Gordon JI. An obesity-associated gut microbiome with increased capacity for energy harvest. Nature. (2006) 444:1027-31. doi: 10.1038/nature05414

34. Victora CG, Adair L, Fall C, Hallal PC, Martorell R, Richter L, et al. Maternal and child undernutrition: consequences for adult health and human capital. Lancet. (2008) 371:340-57. doi: 10.1016/S0140-6736(07)61692-4

35. Yatsunenko T, Rey FE, Manary MJ, Trehan I, Dominguez-Bello MG, Contreras $\mathrm{M}$, et al. Human gut microbiome viewed across age and geography. Nature. (2013) 486:222-57. doi: 10.1038/nature11053

36. Perumal N, Gaffey MF, Bassani DG, Roth DE. WHO child growth standards are often incorrectly applied to children born preterm in epidemiologic research. J Nutr. (2015) 145:2429-39. doi: 10.3945/jn.115.214064

37. World Health Organization. Shanghai Consensus on Healthy Cities 2016. Health Promot Int. (2017) 32:603-5. doi: 10.1093/heapro/dax038

38. Tremblay MS, LeBlanc AG, Kho ME, Saunders TJ, Larouche R, Colley RC, et al. Systematic review of sedentary behaviour and health indicators in school-aged children and youth. Int J Behav Nutr Phys Act. (2011) 8:98. doi: 10.1186/1479-5868-8-98

39. Flegal KM, Carroll MD, Kit BK, Ogden CL. Prevalence of obesity and trends in the distribution of body mass index among US adults, 1999-2010. JAMA. (2012) 307:491-7. doi: 10.1001/jama.2012.39

40. Holick MF, Binkley NC, Bischoff-Ferrari HA, Gordon CM, 25Hanley DA, Heaney RP, et al. Evaluation, treatment, and prevention of vitamin D deficiency: an endocrine society clinical practice guideline. J Clin Endocrinol Metab. (2011) 96:1911-30. doi: 10.1210/jc.2011-0385

41. Satcher D. From the surgeon general. Sharing an agenda for children: progress and challenges related to the 1990 world summit for Children goals. JAMA. (2001) 286:1305. doi: 10.1016/S0033-3549(04)50028-6

42. Schirnding YV. The world summit on sustainable development: reaffirming the centrality of health. Global Health. (2005) 1:8. doi: 10.1186/1744-8603-1-8

43. Sampson HA. Prevention of atopy and allergic disease: type of infant formula. Nestle Nutr Workshop Ser Pediatr Program. (2012) 57:10917. doi: $10.1159 / 000091068$ 
44. Ma Y, Ma S, Chang L, Wang HJ, Ga Q, Ma L, et al. Gut microbiota adaptation to high altitude in indigenous animals. Biochem Biophys Res Commun. (2019) 516:120-6. doi: 10.1016/j.bbrc.2019.05.085

45. Chi X, Gao H, Wu G, Qin W, Song PF, Wang L, et al. Comparison of gut microbiota diversity between wild and captive bharals (Pseudois nayaur). BMC Vet Res. (2019) 15:243. doi: 10.1186/s12917-019-1993-7

46. Jandhyala SM, Talukdar R, Subramanyam C, Vuyyuru H, Sasikala M, Reddy DN. Role of the normal gut microbiota. World J Gastroenterol. (2015) 21:8787-803. doi: 10.3748/wjg.v21.i29.8787

47. Luo YJ, Chen Y, Liu F, Jiang C, Jiang CH, Gao YQ. Mitochondrial genome sequence of the Tibetan wild ass (Equus kiang). Mitochondrial DNA. (2011) 22:6-8. doi: 10.3109/19401736.2011.588221

48. Schiffrin EJ, Blum S. Interactions between the microbiota and the intestinal mucosa. Eur J Clin Nutr. (2002) 56 (Suppl. 3):S60-4. doi: 10.1038/sj.ejcn.1601489

49. Vrese MD, Schrezenmeir J. Probiotics, prebiotics, and synbiotics. $A d v$ Biochem Eng Biotechnol. (2008) 111:1-66. doi: 10.1007/10_2008_097

50. Gao XL, Jia RZ, Xie L, Kuang LH, Feng L, Wan C. A study of the correlation between obesity and intestinal flora in school-age children. Sci Rep. (2018) 8:14511. doi: 10.1038/s41598-018-32730-6

51. Guarino A, Wudy A, Basile F, Ruberto E, Buccigrossi V. Composition and roles of intestinal microbiota in children. $J$ Matern Fetal Neonatal Med. (2012)25 (Suppl. 1):63-6. doi: 10.3109/14767058.2012.6 63231

52. Biasucci G, Rubini M, Riboni S, Morelli L, Bessi E, Retetangos C. Mode of delivery affects the bacterial community in the newborn gut. Early Hum Dev. (2010) 86 (Suppl. 1):13-5. doi: 10.1016/j.earlhumdev.2010. 01.004

53. Rutayisire E, Huang K, Liu YH, Tao FB. The mode of delivery affects the diversity and colonization pattern of the gut microbiota during the first year of infants' life: a systematic review. BMC Gastroenterol. (2016) 16:86. doi: 10.1186/s12876-016-0498-0

54. Licari A, Manti S, Marseglia A, Brambilla I, Votto M, Castagnoli R, et al. Food allergies: current and future treatments. Medicina. (2019) 55:120. doi: 10.3390/medicina550 50120

55. Patel N, Herbert L, Green TD. The emotional, social, and financial burden of food allergies on children and their families. Allergy Asthma Proc. (2017) 38:88-91. doi: 10.2500/aap.2017.38. 4028

56. Martinis MD, Sirufo MM, Viscido A, Ginaldi L. Food allergies and ageing. Int J Mol Sci. (2019) 20:5580. doi: 10.3390/ijms20225580

57. Anagnostou K. Food immunotherapy for children with food allergies: state of the art and science. Curr Opin Pediatr. (2018) 30:798-805. doi: 10.1097/MOP.0000000000 000684

58. Chan CJ, Richardo T, Lim RLH. Current trend in immunotherapy for peanut allergy. Int Rev Immunol. (2018) 37:27990. doi: 10.1080/08830185.2018.1509967

59. Abrams EM, Chan ES, Sicherer S. Peanut allergy: new advances and ongoing controversies. Pediatrics. (2020) 145:e20192102. doi: 10.1542/peds.2019-2102

60. Feng C, Kim JH. Avoidance B. The psychosocial impact of food allergies. Clin Rev Allergy Immunol. (2019) 57:74-82. doi: 10.1007/s12016-018-8708-x
61. Fong AT, Katelaris CH, Wainstein BK. Bullying in Australian children and adolescents with food allergies. Pediatr Allergy Immunol. (2018) 29:7406. doi: 10.1111/pai.12955

62. Shu SA, Yuen AWT, Woo E, Chu KH, Kwan HS, Yang GX, et al. Microbiota and food allergy. Clin Rev Allergy Immunol. (2019) 57:8397. doi: 10.1007/s12016-018-8723-y

63. Nance CL, Deniskin R, Diaz VC, Paul M, Anvari S, Anagnostou A. The role of the microbiome in food allergy: a review. Children. (2020) 7:e50. doi: 10.3390/children7060050

64. Brown T, Moore TH, Hooper L, Gao Y, Zayegh A, Ijaz S, et al. Interventions for preventing obesity in children. Cochrane Db Syst Rev. (2019) 7:CD001871. doi: 10.1002/14651858.CD001871.pub4

65. Lobstein T, Jackson-Leach R, Moodie ML, Hall KD, Gortmaker SL, Swinburn BA. Child and adolescent obesity: part of a bigger picture. Lancet. (2015) 85:2510-20. doi: 10.1016/S0140-6736(14)61746-3

66. Bass R, Eneli I. Severe childhood obesity: an under-recognised and growing health problem. Postgrad Med J. (2015) 91:63945. doi: 10.1136/postgradmedj-2014-133033

67. Ells LJ, Rees K, Brown T, Mead E, Al-Khudairy L, Azevedo L, et al. Interventions for treating children and adolescents with overweight and obesity: an overview of cochrane reviews. Int J Obes. (2018) 42:182333. doi: 10.1038/s41366-018-0230-y

68. Enright G, Allman-Farinelli M, Redfern J. Effectiveness of family-based behavior change interventions on obesity-related behavior change in children: a realist synthesis. Int J Environ Res Public Health. (2020) 17:4099. doi: 10.3390/ijerph17114099

69. Morales Camacho WJ, Molina Díaz JM, Plata Ortiz S, Plata Ortiz JE, Morales Camacho MA, Patricia Calderón B. Childhood obesity: aetiology, comorbidities, and treatment. Diabetes Metab Res Rev. (2019) 35:e3203. doi: 10.1002/dmrr.3203

70. Gao Y, Ge L, Shi SZ, Sun Y, Liu M, Wang B, et al. Global trends and future prospects of e-waste research: a bibliometric analysis. Environ Sci Pollut Res. (2019) 26:17809-17820. doi: 10.1007/s11356-019-05071-8

Conflict of Interest: The authors declare that the research was conducted in the absence of any commercial or financial relationships that could be construed as a potential conflict of interest.

Publisher's Note: All claims expressed in this article are solely those of the authors and do not necessarily represent those of their affiliated organizations, or those of the publisher, the editors and the reviewers. Any product that may be evaluated in this article, or claim that may be made by its manufacturer, is not guaranteed or endorsed by the publisher.

Copyright (C) 2021 Wang, Liu, Chen, Qian, Pan, Ge, Wang, Ding and Wang. This is an open-access article distributed under the terms of the Creative Commons Attribution License (CC BY). The use, distribution or reproduction in other forums is permitted, provided the original author(s) and the copyright owner(s) are credited and that the original publication in this journal is cited, in accordance with accepted academic practice. No use, distribution or reproduction is permitted which does not comply with these terms. 